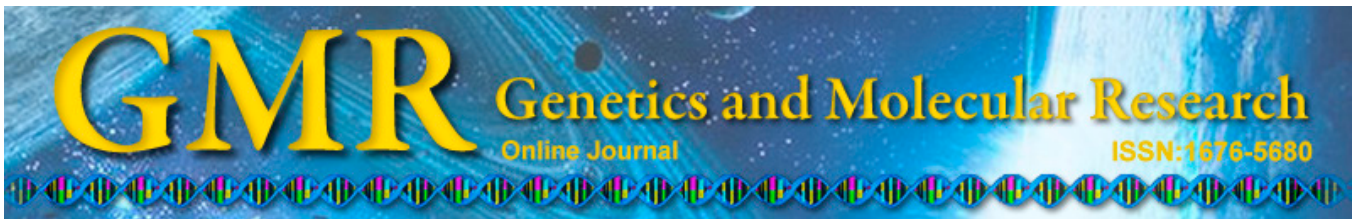

\title{
Establishment of a rabbit model of coronary artery bypass graft and endothelial nitric oxide synthase gene transfection
}

\author{
Y. Zhu, H.-S. Wang, X.-M. Li and Z.-W. Wang \\ Department of Cardiovascular Surgery, PLA Institute of Cardiovascular Disease, \\ Shenyang Military Region General Hospital, Shenyang, Liaoning Province, China \\ Corresponding author: H.-S. Wang \\ E-mail: wanghuishan_whs@yeah.net \\ Genet. Mol. Res. 14 (1): 1479-1486 (2015) \\ Received April 22, 2014 \\ Accepted October 20, 2014 \\ Published February 20, 2015 \\ DOI http://dx.doi.org/10.4238/2015.February.20.3
}

\begin{abstract}
This study established an animal model of coronary artery bypass graft $(\mathrm{CABG})$ surgery. The human endothelial nitric oxide synthase (eNOS) gene was transfected into grafted arterial walls to verify transfection efficiency. Forty rabbits were randomized into the following 4 equal groups: 1 ) eNOS gene transfection group (eNOS group); 2) empty eNOS gene transfection group (empty gene group); 3) control group; 4) normal femoral artery group. Grafted arteries, and normal carotid and femoral artery specimens were obtained 3 weeks later. Immunohistochemistry and analyses of tissue nitric oxide (NO) levels, eNOS activity, and eNOS protein western blotting were performed. The effectiveness and efficiency of transfection were observed and confirmed. All rabbits survived. The grafted arteries retained patency. Varying degrees of adaptability changes were observed in grafted arteries in each group. The eNOS group exhibited vascular wall thickening and significantly increased eNOS protein expression. The control and empty gene groups exhibited vessel wall degeneration, and eNOS protein was weakly or not expressed $(\mathrm{P}<$ 0.05 ). The arterial wall NO concentration and total eNOS activity
\end{abstract}


in the eNOS group were significantly higher than those in the other groups $(\mathrm{P}<0.05)$. Western blotting demonstrated that the vascular wall eNOS protein concentration was significantly greater than that in the other groups $(\mathrm{P}<0.05)$. Furthermore, the eNOS gene transfection can increase eNOS expression and activity in vessel walls, increasing local NO concentration and expression.

Key words: Coronary artery bypass surgery; Grafted artery; Spasm; Endothelial nitric oxide synthase; Gene transfection

\section{INTRODUCTION}

In coronary artery bypass graft (CABG) surgery, appropriately selecting arteries significantly improves the short- and long-term patency rate and success rate of the surgery (Habib et al., 2012) However, the tendency of grafted arteries to spasm affects surgical results and clinical symptoms. Some studies show vasospasms are associated with gene deficiency and low expression levels of vessel wall endothelial nitric oxide synthase (eNOS) (Joannides et al., 1995; He et al., 2011). Therefore, this study aimed to establish a CABG model in rabbits. To this end, the eNOS gene was transfected into the transplanted arterial walls of grafted arteries, and the transfection efficiency was subsequently verified.

\section{MATERIAL AND METHODS}

\section{Materials}

Forty 12 -month-old healthy rabbits weighing $3.0 \pm 0.5 \mathrm{~kg}$ were used; only males were used to eliminate the effect of estrogen on graft vascular endothelial function. All experiment animals were provided by the Experimental Animals Division of Shenyang Military General Hospital. AdCMV eNOS is a replication-defective adenovirus with recombinant genes containing human eNOS; it does not contain any foreign genes but shares the same structure with the adenovirus of AdCMV eNOS. This was provided by Shanghai New Genes Biological Engineering (China).

\section{Animal model establishment}

The rabbits were placed under intramuscular anesthesia with SUMAAN $(10 \mathrm{~mL} / \mathrm{kg})$, and the skin on the surgical fields of neck and thigh were prepared and sterilized. The animals were heparinized by intravenous heparin injection $(1 \mathrm{mg} / \mathrm{kg})$. The incision area was about 5 $\mathrm{cm}$ in the middle area of the neck and thigh, and portions of the carotid and femoral arteries usually $1-1.5 \mathrm{~cm}$ on the right were resected. The location selected was close to the distal segment of the vessel to avoid vascular injury. The resected arteries were immediately washed with washing fluid containing $30 \mathrm{mM}$ nitroglycerin and $30 \mathrm{mM}$ verapamil at room temperature $\left(25^{\circ} \mathrm{C}\right)$ to prevent spasms. They were subsequently immersed in Krebs-Ringer storage buffer (K-R solution) (118 mM NaCl, $4.9 \mathrm{mM} \mathrm{KCl}, 2.5 \mathrm{mM} \mathrm{CaCl}_{2}, 1.2 \mathrm{mM} \mathrm{MgSO}_{4}, 25 \mathrm{mM}$ $\mathrm{NaHCO}_{3}, 1.2 \mathrm{mM} \mathrm{KH}_{2} \mathrm{PO}_{3}, 5.5 \mathrm{mM}$ glucose, and $0.03 \mathrm{mM}$ EDTA) in $95 \% \mathrm{O}_{2}$ and $5 \% \mathrm{CO}_{2}$. 
Blood gas analysis showed that $\mathrm{PaO}_{2}$ and $\mathrm{PaCO}_{2}$ were 200 and $40 \mathrm{mmHg}$, respectively, and $\mathrm{pH}$ was 7.4-7.5. The femoral artery was obtained as described above, and 9-0 Prolene was used for the autologous femoral-carotid artery anastomosis. An average of 8-11 stitches were made on each side. The resected carotid artery segments were connected with the defect in the autologous femoral artery to avoid the lower-limb necrosis. Patency and a lack of distortion and bleeding were observed, and the incision was sutured layer by layer. In order to avoid interorganizational interaction, only one side of autologous arterial grafts was performed in each rabbit. The experimental animals were sent to the Experimental Animal Center after recovering from anesthesia. Penicillin 30,000 U/kg was injected intramuscularly for 3 consecutive days as prophylaxis. Aspirin powder $(20 \mathrm{mg} /$ day) was added to food to prevent thrombosis. Before the experiments could begin, repeated practice was required until the operator mastered the skill.

\section{Animal grouping}

The 40 rabbits were randomized into 4 equal groups. First, in the eNOS gene transfection group (eNOS group hereafter), the femoral artery was obtained as described above; it was soaked in K-R solution containing human AdCMV eNOS gene adenovirus (viral titer: $5 \times 10^{12} \mathrm{PFU} / \mathrm{L}$ ) at $37^{\circ} \mathrm{C}$ for $1 \mathrm{~h}$ for gene transfection. The CABG model was established as described above. The femoral artery was connected to the carotid artery end to end and transplanted as a bypass arterial graft. Second, in the empty eNOS gene transfection group (empty gene group hereafter), the acquired femoral artery segment was immersed in K-R solution containing empty eNOS gene AdCMV adenovirus (virus titer: $5 \times 10^{12} \mathrm{PFU} / \mathrm{L}$ ) for gene transfection. The remaining procedures were the same as the eNOS group. Third, in the control group, the femoral artery was resected for the bypass arterial graft. However, gene transfection was not performed. Fourth, in the sham operation group, neither gene transfection nor vascular grafting was performed but the femoral artery was resected and reconnected.

\section{Detection methods}

Three weeks after surgery, the transplanted carotid artery segments were obtained under anesthesia. The corresponding femoral artery segments were obtained in the normal femoral artery group. Five arteries were obtained in each group, and tissue homogenates were prepared. First, nitric oxide (NO) concentration of the vessel wall was detected by the nitrate reductase method using an NO kit from Nanjing Jiancheng Biotechnology (China). Second, the total eNOS activity of the vessel wall was detected by the chemical calorimetry method using a total eNOS activity kit from Nanjing Jiancheng Biotechnology. Finally, eNOS protein concentration of the vascular wall was analyzed by western blotting. The blots were quantitatively analyzed using the Fluor Chem V 2.0 gel image analysis software (USA). Five additional arteries from each group were soaked in $4 \%$ paraformaldehyde solution. The sections were embedded in paraffin, stained with hematoxylin and eosin, and the pathological morphology was observed. Streptavidin peroxidase immunohistochemical staining was also used to detect eNOS protein expression. 


\section{Statistical analysis}

Data are reported as means \pm standard deviation. The samples were normally distributed, consistent with homogeneity of variance. The Student $t$-test was used for comparisons among groups. Analyses were performed by the Division of Biostatistics, China Medical University using SPSS version 14.0. $\mathrm{P}<0.05$ was considered to be significant.

\section{RESULTS}

\section{General observations}

All rabbits survived. Surgical wounds only exhibited a slight inflammatory reaction in the control and normal femoral artery groups. Perivascular inflammation was slightly greater in the eNOS and empty gene groups, and the blood vessels and surrounding tissue exhibited different degrees of adhesion. All femoral arteries maintained patency; the outer diameter of blood vessels was thickened, and the lumen was enlarged.

\section{Histopathology}

Histopathological changes are shown in Figure 1. Compared to the normal femoral group, arterial walls were slightly thickened in the eNOS group under low magnification, mainly due to smooth muscle layer thickening. The microscopic changes in the control and empty gene groups were consistent. The arterial wall was thickened, the elastic fibers in the middle membrane had thickened significantly, the arterial wall exhibited hyaline degeneration, and many vacuoles were observed.

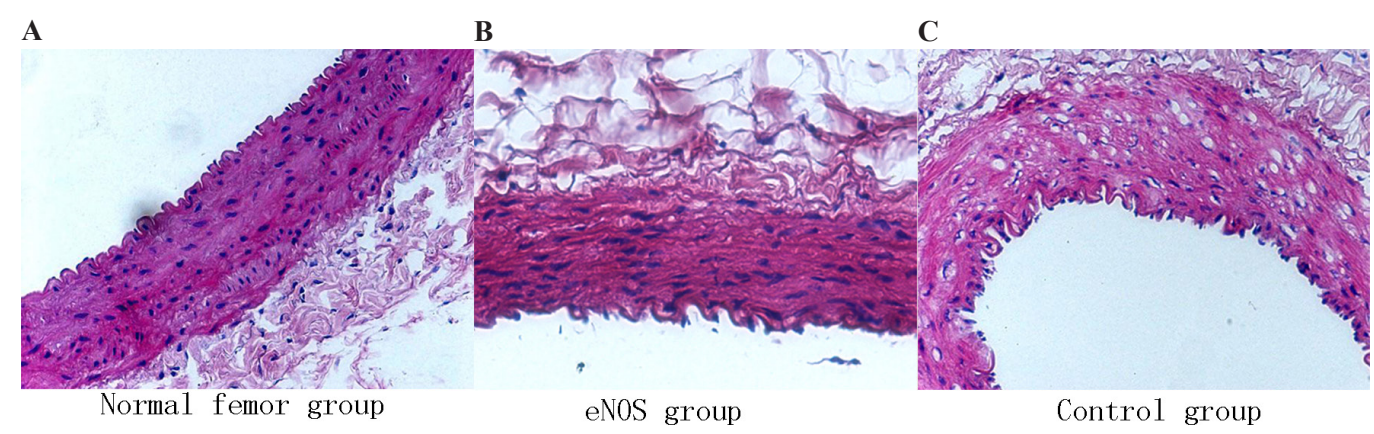

Figure 1. Femoral artery wall (hematoxylin and eosin, 20X). A. Normal femoral artery group. B. eNOS control group. C. Control group.

\section{eNOS protein expression}

Strong eNOS protein expression was detected in the media, intima, and adventitia of grafted vessel walls in the eNOS group (Figure 2). The other groups exhibited no eNOS protein expression; this suggests that after gene transfection, the eNOS gene can be overexpressed in the media, intima, and adventitia of grafted vessel walls. 
$\mathbf{A}$

B C
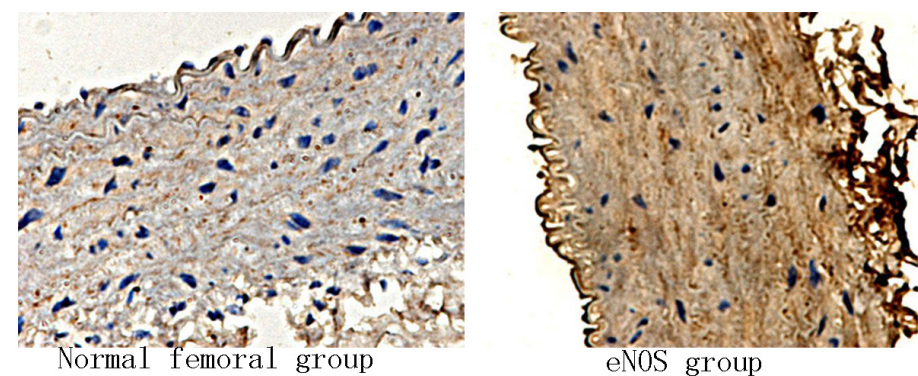

eNOS group

C

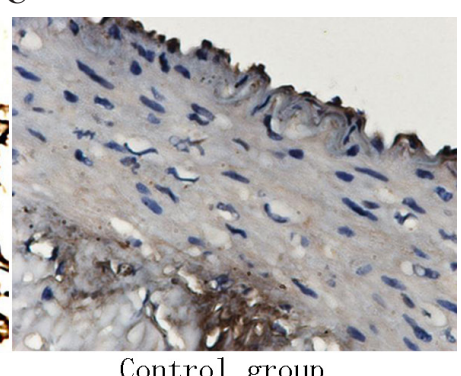

Control group

Figure 2. eNOS protein expression of the femoral artery (immunohistochemistry, 40X). A. Normal femoral artery group. B. eNOS control group. C. Control group.

\section{NO levels, total eNOS activity detection, and western blot analysis in vessel wall tissues}

The eNOS protein expression in the vascular wall, NO levels, total eNOS activity, and eNOS protein expression in the eNOS group differed significantly from the other 3 groups $(\mathrm{P}<0.05)$, while the differences among the remaining groups were not significant $(\mathrm{P}>0.05)$ (Table 1, Figure 3).

Table 1. NO content, total eNOS activity, and gray values in western blot analysis of eNOS protein expression in vessel walls $(\mathrm{N}=5$, means $\pm \mathrm{SD})$.

\begin{tabular}{lccc}
\hline & NO content $(\mu \mathrm{M} / \mathrm{g})$ & Total eNOS activity $(\mathrm{U} / \mathrm{mg})$ & Gray value of eNOS protein expression \\
\hline eNOS group & $8.83 \pm 1.24^{\mathrm{a}}$ & $0.987 \pm 0.239^{\mathrm{a}}$ & $111.12 \pm 29.36^{\mathrm{a}}$ \\
Empty gene group & $5.24 \pm 1.08$ & $0.261 \pm 0.034$ & $48.84 \pm 13.17$ \\
Control group & $5.17 \pm 1.02$ & $0.251 \pm 0.063$ & $45.01 \pm 11.45$ \\
Normal femoral group & $5.07 \pm 0.98$ & $0.249 \pm 0.041$ & $44.47 \pm 12.91$ \\
\hline
\end{tabular}

${ }^{\mathrm{a} C}$ Compared to empty gene group, control group, and normal femoral group, $\mathrm{P}<0.05$.

1

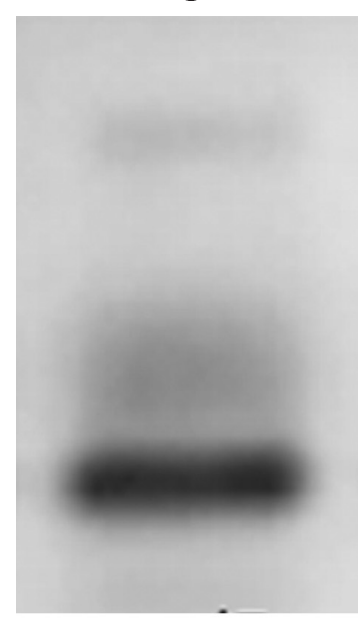

eNOS GROLP
2
3
4

Figure 3. Expression of eNOS in the vessel wall with western blot analysis in each group. Lane $1=$ eNOS group. Lane 2 = empty gene group. Lane $3=$ control group. Lane $4=$ normal femoral artery group. 


\section{DISCUSSION}

In the present study, the grafted blood vessels used were arteries, because they have high long-term patency; this choice is universally accepted (Achouh et al., 2012). However, the tendency for arteries to spasm is one of the main factors preventing a wider range of applications (Kobayashi, 2009). Thus, resolving this tendency would significantly improve both the short- and long-term patency of grafted arteries in patients with coronary artery disease, consequently improving clinical outcomes. At present, clinical long-term treatment with drugs alone does not adequately alleviate vasospasms in grafted arteries. NO can balance endogenous vasoconstrictor substances and is one of the main factors causing blood vessel wall dilation (Kooijman et al., 2008; Yoo and Kim, 2009). Furthermore, vasospasms of bypass grafted arteries are associated with decreased levels of endogenous NO. Increasing the NO concentration of local grafted arterial wall may reduce and prevent vasospasm to some extent (Wu et al., 2005; Nowicki et al., 2011). However, NO has a partial dispersion action mechanism, short biological half-life (10-60 s), and unstable chemical structure. Furthermore, exogenously delivered NO cannot be stored, adjusted, or released through traditional adjustment mechanisms. Therefore, only local endogenous synthesis can be increased (Bellien et al., 2012). The key enzyme in NO synthesis in the human body is NOS (Gilani et al., 2007; Seddon et al., 2009), which has 3 isoforms; however, eNOS is the only one that can be structurally expressed on blood vessel walls. Gene transfection is an effective method for increasing the eNOS expression of vascular walls and thus local NO concentration. In addition, after CABG surgery, the grafted arteries reside in a complex environment in vivo, where they can be easily influenced and affected by neuronal, humoral, and endocrine factors as well as a variety of drugs. It is difficult to determine the effects of a single or several expected factors on vascular wall contraction and relaxation. However, in vivo human gene transfection experiments and vascular function studies would be medically unethical. Therefore, we designed an appropriate animal model, which was subsequently used for gene transfection experiments. Thus, we aim to find an approach for improving arterial vasospasms by using this model.

In organizational structure classification, the main trunks of the coronary and carotid arteries are class I, while the commonly used grafted radial and distal femoral arteries are class II (Stähli et al., 2006). Class II vessels are muscular blood vessels with highly condensed medial smooth muscle cells; $\alpha 1$-adrenergic receptors are widely distributed, making these vessels more sensitive to catechol stimulation and thus vasospasms (Bellien et al., 2012). In the animal model established herein, we used a small part of the femoral artery to replace the carotid artery; thus, class II blood vessels were subjected to the pressure and surrounding environment of class I blood vessels. To some extent, the effects of the flow, pressure changes, paracrine inflammatory mediators, and other changes in the inner environment on the grafted arteries can be simulated in vivo (Zhang, 2007). The specimens were obtained 3 weeks after animal feeding, and general observations confirmed that the grafted femoral arteries exhibited thickened vascular diameter, luminal dilation, and other adaptive changes. This is the result of adaptive hypertrophy in vessel walls; in particular, the medial membrane exhibited varying degrees of elastic fiber thickening, and the smooth muscle layer was more condensed. We also separately calculated the contraction curve of phenylephrine concentration with respect to resting tension of the vessel wall in carotid and grafted arteries; they exhibited similarities in contraction, confirming the feasibility of the technique.

The gene transfection experiments using the animal model show significant vessel 
wall thickening in not only the normal femoral artery group, but also control and empty gene groups. The inner and outer membranes showed no increase in eNOS protein expression, the medial wall exhibited hyaline degeneration, and substantial vacuolization was observed. The arterial walls were slightly thickened in the eNOS group, whereas the elastic fibers in the membrane did not thicken significantly. Meanwhile, eNOS protein expression increased significantly. The results also confirm that eNOS has a regulatory role in the suitability of vessel walls. Gene transfection increase the total eNOS activity of vessel wall tissues in the eNOS group 3.82 fold $(0.987 \pm 0.239 \mathrm{U} / \mathrm{mg})$ compared to the average of the other 3 groups; furthermore, NO concentration was $70.8 \%$ greater $(8.83 \pm 1.24 \mu \mathrm{M} / \mathrm{g})$ than that in the control. Western blot analysis showed eNOS gene transfection significantly increased the eNOS protein concentration of vascular walls. The gray value of eNOS protein was $111.12 \pm 29.36$, which was 2.2-2.4 times that of the other groups $(\mathrm{P}<0.05)$. The eNOS protein concentrations of the vessel walls in the control and empty gene groups were not significantly different from those in the normal femoral artery group $(\mathrm{P}>0.05)$; this is consistent with vascular wall NO concentration and eNOS activity the corresponding groups. Thus, the results confirm that gene transfection can enhance the eNOS gene expression of the target vessel wall. Furthermore, eNOS gene overexpression improved the target vessel wall eNOS protein concentration and activity, ultimately increasing vascular wall NO concentration. We will verify the association between increased $\mathrm{NO}$ concentration and vasospasms in follow-up experiments.

The establishment of the present animal model is concordant with the hemodynamic characteristics of CABG surgery, including vascular pressure changes, level matching, and other requirements. The adenovirus-mediated transfection of target genes significantly increases eNOS expression and concentration in the outer, middle, and inner membranes, consequently increasing the eNOS activity and NO concentrations. Thus, this model can be applied to study the spastic features of grafted arteries in CABG as well as eNOS and NO concentrations.

\section{REFERENCES}

Achouh P, Isselmou KO, Boutekadjirt R, D'Alessandro C, et al. (2012). Reappraisal of a 20-year experience with the radial artery as a conduit for coronary bypass grafting. Eur. J. Cardiothorac. Surg. 41: 87-92.

Bellien J, Iacob M, Remy-Jouet I, Lucas D, et al. (2012). Epoxyeicosatrienoic acids contribute with altered nitric oxide and endothelin-1 pathways to conduit artery endothelial dysfunction in essential hypertension. Circulation 125: 12661275.

Gilani M, Kaiser DR, Bratteli CW, Alinder C, et al. (2007). Role of nitric oxide deficiency and its detection as a risk factor in pre-hypertension. J. Am. Soc. Hypertens. 1: 45-55.

He GW, Fan L, Grove KL, Furnary A, et al. (2011). Expression and function of endothelial nitric oxide synthase messenger RNA and protein are higher in internal mammary than in radial arteries. Ann. Thorac. Surg. 92: 845-850.

Habib RH, Schwann TA and Engoren ML (2012). Late effects of radial artery versus saphenous vein grafting in patients aged 70 years or older. Ann. Thorac. Surg. 94: 1478-1484.

Joannides R, Haefeli WE, Linder L, Richard V, et al. (1995). Nitric oxide is responsible for flow-dependent dilatation of human peripheral conduit arteries in vivo. Circulation. 91: 1314-1319.

Kobayashi J (2009). Radial artery as a graft for coronary artery bypass grafting. Circ. J. 73: 1178-1183.

Kooijman M, Thijssen DH, de Groot PC, Bleeker MW, et al. (2008). Flow-mediated dilatation in the superficial femoral artery is nitric oxide mediated in humans. J. Physiol. 586: 1137-1145.

Nowicki M, Misterski M, Malinska A, Perek B, et al. (2011). Endothelial integrity of radial artery grafts harvested by minimally invasive surgery - immunohistochemical studies of CD31 and endothelial nitric oxide synthase expressions: a randomized controlled trial. Eur. J. Cardiothorac. Surg. 39: 471-477.

Seddon M, Melikian N, Dworakowski R, Shabeeh H, et al. (2009). Effects of neuronal nitric oxide synthase on human coronary artery diameter and blood flow in vivo. Circulation 119: 2656-2662. 
Stähli BE, Greutert H, Mei S, Graf P, et al. (2006). Absence of histamine-induced nitric oxide release in the human radial artery: implications for vasospasm of coronary artery bypass vessels. Am. J. Physiol. Heart. Circ. Physiol. 290: H1182-1189.

Wu X, Chen YK, Ma LT, Lian E, et al. (2005). Type induced nitric oxide synthase in the role of late-onset vasospasm. Zhonghua shi yan wai ke za zhi 12: 203-205.

Yoo SY and Kim JY (2009). Recent insights into the mechanisms of vasospastic angina. Korean Circ. J. 39: 505-511.

Zhang YY, Ge W, Yuan B, Xu R, et al. (2007). The New Zealand rabbit limbs artery vascular morphology changes after transplantation. Zhonghua shi yan wai ke za zhi 24: 506. 